\title{
Cervical ectopic pregnancy
}

\author{
Asha Bhalwal', Olivia Dziadek ${ }^{1 *}$, Ramesha Papanna ${ }^{2}$, Kenneth Moise ${ }^{2}$, John Hardy ${ }^{3}$ and Alvaro Montealegre ${ }^{1}$ \\ ${ }^{1}$ Department of Obstetrics, Gynecology and Reproductive Sciences, McGovern Medical School, University of Texas Health Science Center (UTHealth), \\ 6410 Fannin Street, Suite 250, Houston, Texas 77030. \\ ${ }^{2}$ Department of Obstetrics, Gynecology and Reproductive Sciences, McGovern Medical School, University of Texas Health Science Center (UTHealth), \\ Division of Maternal Fetal Medicine, 6410 Fannin Street, Suite 250, Houston, Texas 77030.
}

${ }^{3}$ Perinatal Associates of San Antonio ,4458 Medical Drive, Suite 405, San Antonio, Texas 78229.

*Corresponding Author: Olivia Dziadek, Department of Obstetrics, Gynecology and Reproductive Sciences McGovern Medical School, University of Texas Health Science Center (UTHealth) McGovern Medical School

\section{Received date: June 01, 2021; Accepted date: June 15, 2021; Published date: August 18, 2021}

Citation: Bhalwal A., Dziadek O., Papanna R. , Moise K., Hardy J. and Montealegre A. (2021) Cervical ectopic pregnancy. J.Obstetrics Gynecology and Reproductive Sciences. 5(6): DOI: 10.31579/2578-8965/075

Copyright: (02021, Olivia Dziadek, This is an open access article distributed under the Creative Commons Attribution License, which permits unrestricted use, distribution, and reproduction in any medium, provided the original work is properly cited.

\begin{abstract}
We performed dilation and curettage and cervical balloon placement in a cervical ectopic pregnancy after treatment with Methotrexate, KCI and bilateral uterine artery embolization. A minimally invasive approach was used in the case as the patient desired future fertility. We present the potential challenges in management of cervical ectopic pregnancy as well as approaches to treatment.

Key words: cervical pregnancy; fertility; uterine artery embolization
\end{abstract}

\section{Introduction}

Cervical pregnancy is a type of ectopic pregnancy that results from implantation of a fertilized ovum in the endocervical canal below the level of the internal os (10). The incidence of cervical ectopic pregnancy is less than $0.1 \%$ of all ectopic pregnancies (10), and is a very serious condition due to risk of life-threatening hemorrhage. Risk factors include previous endometrial curettage, previous cesarean section, endometrial inflammation from the use of an intrauterine device or pelvic inflammatory disease (5), and assisted reproductive technologies. Other risk factors include: induced abortion, Asherman's syndrome, leiomyomata, and prior in utero exposure to diethylstilbestrol (4). The diagnosis include symptomatology and ultrasound imaging. The most common symptom is painless vaginal bleeding and delayed diagnosis may result in massive bleeding and hypovolemic shock. The management of a cervical ectopic pregnancy is tailored to the patient's individual fertility desires and the complexity of the case, given the rarity of nontubal ectopic pregnancies (11)

We present a case of a patient diagnosed with cervical ectopic pregnancy in the late first trimester. The patient desired future fertility.

\section{Case Description:}

A 27 year old patient was referred to our group from a gynecologist's office with cervical ectopic pregnancy. Her obstetrical history was significant for two pregnancies and one term vaginal delivery with no associated complications. She had no risk factors associated with cervical pregnancy and she prese1nted with no vaginal bleeding or systemic discomfort.

On examination, her cervix was dilated to one centimeter and completely effaced. Transvaginal ultrasonography revealed a cervical length at external os of $3 \mathrm{~mm}$ and a gestational sac in the cervical canal beneath the internal cervical os and an empty uterus. Measurement of the fetus had crown rump length consistent with 11 weeks and 6 days, as expected by the patient's last menstrual period. Serum human chorionic gonadotrophic hormone level was $75,097 \mathrm{mIU} / \mathrm{ml}$ on first assessment.

The patient desired future fertility and treatment options were presented in accordance to this goal. The risk of intra-operative bleeding with dilation and curettage was reviewed. The patient agreed to undergo Methotrexate injection, bilateral uterine artery embolization followed by suction dilatation and curettage.

On hospital day \#1, the patient underwent treatment with one dose of Methotrexate and bilateral uterine artery embolization. Angiography of the bilateral internal iliac arteries demonstrated arterial enhancement of cervical ectopic pregnancy arising from multiple tortuous branches from bilateral uterine arteries.

On hospital day \#2, the patient was taken to the operating room where a potassium chloride injection was administered to the products of conception until cessation of fetal heart tones were noted on ultrasound. Placement of cervical sutures at 3 and 9 o'clock was then performed to 
occlude the descending branches of the uterine arteries followed by a careful suction dilation and curettage under ultrasound guidance.

An ultrasound performed after the procedure ensured evacuation of products of conception. A cervical Cook balloon was placed under ultrasound guidance with $80 \mathrm{cc}$ of normal saline infused into the balloon catheter to provide hemostasis.

On postoperative day one, the cook balloon was removed with little to no bleeding noted. She was discharged home with bleeding precautions and a close follow up with her primary provider was scheduled. After her surgery, she has been followed by her primary provider and beta HCG levels have trended down adequately.

\section{Discussion}

Cervical pregnancies are rare, accounting for less than $0.1 \%$ of all ectopic pregnancies. Our case study is significant given its late gestational age on presentation and lack of symptoms. This patient was referred at 11 weeks with diagnosis confirmed by ultrasound. Given her interest in preserving fertility, the treatment was guided away from hysterectomy. Uterine artery embolization, methotrexate injection and potassium chloride injection of the products of conception were completed with the goal of reducing blood loss at the time of suction dilatation and curettage. According to Zakaria, uterine artery embolization in conjunction with multi dose Methotrexate therapy has been shown to be a safe and effective option for the conservative treatment of cervical ectopic pregnancy and in cases of fetal cardiac activity, intra-amniotic $\mathrm{KCl}$ may be administered in addition to Methotrexate [15].

A dose of Methotrexate was given as a DNA synthesis inhibitor to decrease cell reproduction and growth of trophoblastic and fetal cells in the interest of decreasing overall blood loss.

Methotrexate can be injected intramuscularly, intra-cervically or intraamniotically at a dose of $50 \mathrm{mg} / \mathrm{m} 2$. Approximately $49 \%$ of patients will require a surgical procedure despite treatment with Methotrexate (5).

Pretreatment HCG levels greater than 5,000 $\mathrm{mIU} / \mathrm{ml}$ and fetal cardiac activity are relative contraindications to Methotrexate use, although a review article by Cheung suggests that ultrasound guided local methotrexate injection could be considered as a first-line treatment modality for cesarean scar pregnancy in women with serum human chorionic gonadotropin levels no higher than 100,000 $\mathrm{mIU} / \mathrm{mL}$ (3). Given the gestational age of the pregnancy and the short period of time between injection and operative treatment with suction $\mathrm{D} \& \mathrm{C}$, in retrospect, we concluded, that this step in our protocol may have not been warranted.

Uterine artery embolization was performed by our radiology department through percutaneous transcatheter embolization of polyvinyl alcohol microspheres under fluoroscopic guidance.

These particles are carried by the arterial blood flow to occlude the uterine arteries distally. The vessels feeding the pregnancy are preferentially occluded due to their larger caliber and higher flow. There has been a debate regarding potential risk of uterine artery embolization, potentially causing reduction of ovarian blood supply, reducing circulating AMH levels. A meta-analysis studying the impact of uterine artery embolization on circulating AMH levels among women under and over 40 years of age showed no difference in circulating AMH levels at 3, 6 and 12 months (12). Thus, there is evidence that uterine artery embolization is an acceptable form of management in patients desiring future fertility. In the case of our patient, we counseled her about the temporary occlusion of the uterine vessels for 2 to 6 weeks (5) from UAE and its advantage is prevention of hemorrhage. Available data suggest a modest to minimal negative impact on fertility.
Immediately prior to performing suction dilatation and curettage, we injected the products of conception with potassium chloride at a dose of $14.9 \mathrm{~g} / 100 \mathrm{ml}$. A total of $2 \mathrm{~mL}$ was needed for cessation of pulsations. The reason for using potassium chloride is that therapeutic intra-amniotic demise may lead to fewer maternal morbidity events, including less bleeding and shorter hospital stays (15). In an article by Trambert et al, due to the low number of cervical ectopic cases treated with KCI, it was difficult to determine if intra-amniotic KCI injection is necessary to successfully resolve a cervical ectopic pregnancy. We believe that this step did not have an effect on our overall blood loss. Of note, cervical sutures were placed to occlude the descending branches of the uterine arteries and a careful suction dilatation and curettage was then performed without difficulty and encountering minimal bleeding.

An ultrasound performed after the procedure ensured complete evacuation of products of conception. We finished the procedure by placing a prophylactic Cook balloon to tamponade the cervical blood vessels.

All tissue was submitted to pathology, confirming chorionic villi and fetal parts.

Regarding pathology, the criteria for the diagnosis of cervical pregnancy was established by Isidor Rubin (Rubin 1911) and consisted of the following: cervical glands must be opposite the placental attachment, placental attachment to the cervix must be situated below the entrance of the uterine vessels or below the peritoneal reflection of the anterior and posterior surfaces of the uterus and fetal elements must be absent from the corpus uteri.

Dilation and curettage carries a $40 \%$ risk for hysterectomy, and improved outcome is noted with concurrent uterine artery embolization (5). Total abdominal hysterectomy is the treatment of choice for patients in whom future fertility is not desired, or in the setting of unstable vital signs secondary to excessive vaginal bleeding (5). Cervical sutures may be placed to occlude the descending branches of the uterine arteries followed by suction and curettage and placement of cervical balloon post curettage (13).

The impact of cervical ectopic pregnancy on future fertility as well as recurrence risk is unknown and patients should be counseled appropriately.

\section{Conclusion}

This is a case of late first trimester cervical ectopic pregnancy that was managed successfully with Methotrexate, uterine artery embolization, followed by dilation and curettage \& cervical balloon placement. Cervical ectopic pregnancy carries a high risk of hemorrhage necessitating efforts to reduce bleeding, as with uterine artery embolization. Uterine artery embolization was performed prior to dilation and curettage due to its ability to reduce risk of hemorrhage. This case demonstrates a successful conservative approach in management of cervical ectopic pregnancy

\section{References:}

1. Amato, Paula. (2014) Diagnosis and Management of Cevical Ectopic pregnancy. Pearls of excellence.Published online January 1,. Accessed 30 November 2019.

2. El Shamy, Amer SAK, Mohamed AA, James C, Jayaprakasan $\mathrm{K}$. The impact of uterine artery embolization on ovarian reserve: A systematic review and meta-analysis. Acta Obstet Gynecol

3. Scand. (2019) Aug 1.

4. Cheung, Vincent. 2015) Local Methotrexate Injection as the first line treatment for cesarean Scar pregnancy: Review of the literature. Journal of Minimally Invasive Gynecology. Volume 22, No 5 . 
5. Fylstra DL. (2012) Ectopic pregnancy not within the (distal) fallopian tube: etiology, diagnosis, and treatment. Am J Obstet Gynecol; 206: 289-299.

6. Hosni, Mohamed.(2014) Diagnostic and Therapeutic dilemmas of Cervical ectopic pregnancy. CME Review Article. Obstetrical and Gynecological Survey. Volume 69. No 5.

7. Hwang JH, Lee JK, Oh MJ, Lee NW, Hur JY, Lee KW. (2010) Classification and management of cervical ectopic pregnancies: experience of a single institution. J Reprod Med;55: 469-76.

8. Kung FT, Chang SY, Tsai YC, Hwang FR, Hsu TY, Soong YK. (1997) Subsequent reproduction and obstetric outcome after methotrexate treatment of cervical pregnancy: a review of original litera-ture and international collaborative follow-up. Hum Reprod 12(3):591-595.

9. Rubin A, (1911)Cervical pregnancy.

10. Schneider, P. Dreizin DH. (1957) Cervical pregnancy. Am $J$ Surg.; 93: 27-40.

11. Singh, Sweta. (2013) Diagnosis and management of cervical ectopic pregnancy. Journal of Huma Reproductive Science. 6 (4) 273-276. Oct-Dec

12. Shah, Jaimin, Nasab Susan, Papanna Ramesha, Chen HanYang, Promecene Pamela, Berens Pamela, Johnson Anthony,
Bhalwal, Asha.(2019) Management and reproductive counseling in cervical, caesarean scar and interstitial ectopic pregnancies over 11 years: identifying the need for a modern management algorithm. Human Reproduction Open, Volume 2019, Issue 4. Published 4 November

13. Shamy, Tarek, Amer Saad, Mohamed Ahmed James, Kathryn, Jayaprakasan Kannamannadiar.( 2019) The impact of uterine artery embolization on ovarian reserve: A systematic review and meta-analysis. August Tang PP, Liu XY, Chen N, et al. Diagnosis and treatment of cervical ectopic pregnancy. 2010;32:497-500.

14. Thomas RL, Gingold BR, Gallagher MW. (1991) Cervical pregnancy: a report of two cases. J Reprod Med; 36:459-62.

15. Trambert JJ, Einstein MH, Banks E, Frost A, Goldberg GL. (2005) Uterine artery embolization in the management of vaginal bleeding from cervical pregnancy: a case series. J Reprod Med;50: 844-50.

16. Zakaria Mark, Abdallah Mazen, Shavell Valerie, Berman Jay, Diamond Michael, Kmak David. (2011) Conservative management of cervical ectopic pregnancy: utility of uterine artery embolization. Fertility and Sterility Vol. 95, No. 3.
This work is licensed under Creative Commons Attribution 4.0 License

To Submit Your Article Click Here: Submit Manuscript

DOI: $10.31579 / 2578-8965 / 075$
Ready to submit your research? Choose Auctores and benefit from:

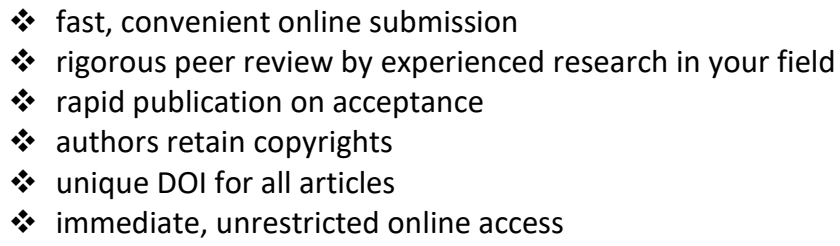

At Auctores, research is always in progress.

Learn more www.auctoresonline.org/journals/obstetrics-gynecology-andreproductive-sciences- 